\title{
ANALISIS SWOT DAN STRATEGI PEMASARAN UNTUK MENINGKATKAN DAYA SAING UKM ES PUTER DI KOTA MALANG
}

\author{
Purnomo 1) $^{\text {1) Yuswono Hadi }}{ }^{2)}$ \\ 1) 2) \\ Teknik Industri Universitas Ma Chung \\ E-mail : pur.nomo@machung.ac.id ${ }^{1)}$; yuswono.hadi@machung.ac.id ${ }^{2)}$
}

\begin{abstract}
Abstraksi
Usaha Kecil dan Menengah (UKM) Es Puter di Kota Malang juga masih menghadapi berbagai permasalahan salah satunya adalah pemasaran. Strategi pemasaran adalah salah satu cara memenangkan keunggulan bersaing yang berkelanjutan baik itu untuk perusahaan yang memproduksi barang atau jasa. Penelitian ini memiliki tujuan untuk: mendapat gambaran mengenai strategi pemasaran untuk meningkatkan daya saing, dan untuk mengetahui seberapa efektif pelaksanaan strategi pemasaran yang telah dilakukan dengan mengidentifikasi dan menjelaskan kekuatan dan kelemahan (lingkungan internal) serta peluang dan ancaman (lingkungan eksternal) serta merumuskan srtategi pemasaran Es Puter yang tepat melalui analisis SWOT (Strengths, Weaknesess, Opportunities, dan Threats). Penelitian ini dilakukan di UKM Es Puter Malang. Metode Penelitian menggunakan pengumpulan datanya dengan dokumentasi, wawancara dan observasi, jenis penelitian deskriptif. Hasil dari analisis efektifitas strategi pemasaran menunjukkan adanya peningkatan yang signifikan.
\end{abstract}

Kata Kunci : UKM, SWOT, Es Puter, Pemasaran, Daya Saing.

\begin{abstract}
Small and Medium Enterprises (SMEs) Ice Puter in Malang also still face various problems one of them is marketing. A marketing strategy is one way of winning a sustainable competitive advantage whether it is for a company that produces goods or services. This research aims to: get an idea of the marketing strategy to improve competitiveness, and to find out how effective the implementation of marketing strategy has been done by identifying and explaining strengths and weaknesses (internal environment) as well as opportunities and threats (external environment) and formulating marketing strategy Puter Ice is right through SWOT analysis (Strengths, Weaknesess, Opportunities, and Threats). This research was conducted in SME Es Puter Malang. Methods The study used data collection with documentation, interviews and observation, type of descriptive research. The results of marketing effectiveness analysis showed a significant improvement.
\end{abstract}

Keywords : SME, SWOT, Ice Puter, Marketing, Competitiveness

\section{Pendahuluan.}

Usaha Kecil dan Menengah (UKM) memegang peranan yang sangat penting bagi perekonomian Indonesia, termasuk di dalamnya adalah perekonomian Kota Malang. Salah satu karakteristik menonjol dari industri modern adalah penerapan fungsi-fungsi manajemen dalam setiap kegiatan perusahaan dengan sungguh-sungguh. Fungsi manajemen ini dapat terdiri dari perencanaan, pelaksanaan, pengendalian, perbaikan ataupun fungsi-fungsi manajemen lain berdasarkan kebutuhan nyata di lapangan.

Dengan demikian industri kecil akan senantiasa siap bersaing dengan siapapun.Usaha
Kecil dan Menengah (UKM) Es puter, adalah sebuah usaha kecil yang bergerak di bidang produksi Es terutama Es Puter. Usaha ini memiliki potensi untuk berkembang lebih besar karena sifatnya yang menghususkan pada industri kreatif. Potensi itu perlu di nyatakan dalam sebuah bentuk pengembangan organisasi untuk merealisasikan kesempatan dan pertumbuhan yang positif Usaha Kecil dan Menengah (UKM) secara nasional, Usaha Kecil dan Menengah (UKM) di Kota Malang juga memiliki peranan yang sangat penting bagi perekonomian Kota Malang, namun demikian perkembangan Usaha Kecil dan Menengah (UKM) di Kota Malang juga masih menghadapi 
berbagai permasalahan. Salah satu Usaha Kecil dan Menengah (UKM) di Kota Malang adalah Usaha Kecil dan Menengah (UKM) Es puter yang juga masih menghadapi berbagai permasalahan. Berdasarkan kondisi tersebut maka pengembangan dan pemasaran Usaha.

\section{Kajian Daya Saing}

Daya saing adalah produktivitas yang didefinisikan sebagai output yang dihasilkan oleh tenaga kerja (Porter, 1990). Daya saing merupakan konsep yang merujuk pada kemampuan suatu perusahaan dalam bersaing dengan perusahaan lainnya untuk menciptakan nilai. Tidak ada satu indikatorpun yang bisa digunakan untuk mengukur daya saing yang memang sangat sulit untuk diukur (Markovics, 2005). Daya saing dapat diciptakan maupun ditingkatkan dengan penerapan strategi bersaing yang tepat, salah satunya dengan pengelolaan sumber daya secara efektif dan efisien. Selain itu, penentuan strategi yang tepat harus disesuaikan dengan seluruh aktivitas dari fungsi perusahaan, sehingga akan menciptakan kinerja perusahaan sesuai dengan yang diharapkan bahkan lebih dan dapat menghasilkan nilai.

\section{Model Analisis SWOT}

Analisis SWOT membandingkan antara faktor eksternal peluang dan ancaman dengan faktor internal kekuatan dan kelemahan. Faktor internal dimasukan kedalam matrik yang disebut matrik faktor strategi internal atau IFAS (Internal Strategic Factor Analisis Summary). Faktor eksternal dimasukkan kedalam matrik yang disebut matrik faktor strategi eksternal EFAS (Eksternal Strategic Factor Analisis Summary). Setelah matrik faktor strategi internal dan eksternal selesai disusun, kemudian hasilnya dimasukkan dalam model kuantitatif, yaitu matrik SWOT untuk merumuskan strategi kompetitif perusahaan. Matrik Factor Strategi Eksternal (EFAS).

Tabel 1. Matrik Faktor Strategi Eksternal (EFAS) (Sumber : Fredi Rangkuti (2004: 18))

\begin{tabular}{|l|c|c|c|c|}
\hline $\begin{array}{c}\text { Faktor } \\
\text { strategi }\end{array}$ & Bobot & Rating & $\begin{array}{c}\text { Bobot } \mathrm{x} \\
\text { Rating }\end{array}$ & Keterangan \\
\hline Peluang & $\mathrm{X}$ & $\mathrm{X}$ & $\mathrm{X}$ & \\
\hline Jumlah & $\mathrm{X}$ & $\mathrm{X}$ & $\mathrm{X}$ & \\
\hline Ancaman & $\mathrm{X}$ & $\mathrm{X}$ & $\mathrm{X}$ & \\
\hline Jumlah & $\mathrm{X}$ & $\mathrm{X}$ & $\mathrm{X}$ & \\
\hline Toral & $\mathrm{X}$ & $\mathrm{X}$ & $\mathrm{X}$ & \\
\hline
\end{tabular}

Tabel 2. Matrik Faktor Strategi Internal

(IFAS) (Sumber : Fredi Rangkuti (2004: 18)

\begin{tabular}{|l|l|l|l|l|}
\hline $\begin{array}{l}\text { Faktor } \\
\text { strategi }\end{array}$ & Bobot & Rating & $\begin{array}{l}\text { Bobot x } \\
\text { Rating }\end{array}$ & Keterangan \\
\hline Kekuatan & $\mathrm{X}$ & $\mathrm{X}$ & $\mathrm{X}$ & \\
\hline Jumlah & $\mathrm{X}$ & $\mathrm{X}$ & $\mathrm{X}$ & \\
\hline KelemahanX & & $\mathrm{X}$ & $\mathrm{X}$ & \\
\hline Jumlah & $\mathrm{X}$ & $\mathrm{X}$ & $\mathrm{X}$ & \\
\hline Toral & $\mathrm{X}$ & $\mathrm{X}$ & $\mathrm{X}$ & \\
\hline
\end{tabular}

\section{Matrik SWOT}

Alat yang digunakan untuk menyusun faktor-faktor strategis perusahaan adalah matrik SWOT. Matrik ini dapat mengambarkan secara jelas bagaimana peluang dan ancaman eksternal yangdihadapi perusahaan dapat disesuaikan dengan kekuatan dan kelemahan yang dimilikinya.

Tabel 3. Matriks SWOT

\begin{tabular}{|c|c|c|}
\hline EFAS & $\begin{array}{l}\text { Kekuatan } \\
\text { (S) } \\
\text { Daftar } \\
\text { kekuatan }\end{array}$ & $\begin{array}{l}\text { Kelemahan } \\
\text { (W) } \\
\text { Daftar } \\
\text { kelemahan }\end{array}$ \\
\hline $\begin{array}{l}\text { Peluang (O) } \\
\text { Daftar peluang }\end{array}$ & $\begin{array}{l}\text { S - O } \\
\text { Strategi } \\
\text { Gunakan } \\
\text { kekuatan } \\
\text { untuk } \\
\text { Meraih } \\
\text { peluang }\end{array}$ & $\begin{array}{l}\text { W -O Strategi } \\
\text { Memperkecil } \\
\text { kelemahan } \\
\text { dengan } \\
\text { Memanfaatkan } \\
\text { peluang }\end{array}$ \\
\hline $\begin{array}{l}\text { Ancaman (T) } \\
\text { Daftar ancaman }\end{array}$ & $\begin{array}{l}\text { S-T Strategi } \\
\text { Gunakan } \\
\text { kekuatan } \\
\text { untuk } \\
\text { menghindari } \\
\text { ancaman }\end{array}$ & $\begin{array}{l}\text { W -T Strategi } \\
\text { Memperkecil } \\
\text { kelemahan dan } \\
\text { menghindari } \\
\text { ancaman }\end{array}$ \\
\hline
\end{tabular}

\section{Metode Penelitian.}

Waktu yang digunakan untuk melakukan penelitian ini adalah pada bulan januari hingga bulan jun 2016.Lokasi penelitian ini bertepat pada UKM Es Puter yang beralamat di jalan Kota Malang. Jenis data yang digunakan pada penelitian ini adalah data kuantitatif dan data kualitatif.

Data kuantitatif yaitu data yang berbentuk angka yang disajikan dalam bentuk informasi baik secara lisan maupun tulisan. Bentuk data ini berbentuk hasil laporan penjualan yang dimiliki oleh perusahaan. Data kualitatif yaitu data yang diperoleh dari objek penelitian. Data yang digunakan juga berasal dari dua sumber, yaitu 
data dari sumber primer dan data dari sumber sekunder. Data primer merupakan data yang dikumpulkan oleh penulis secara langsung dari sumber yang menjadi objek.

\section{Metode Analisis Data}

Metode analisis data dalam penelitian ini menggunakan metode kualitatif, yakni prosedur penelitian yang menghasilkan data

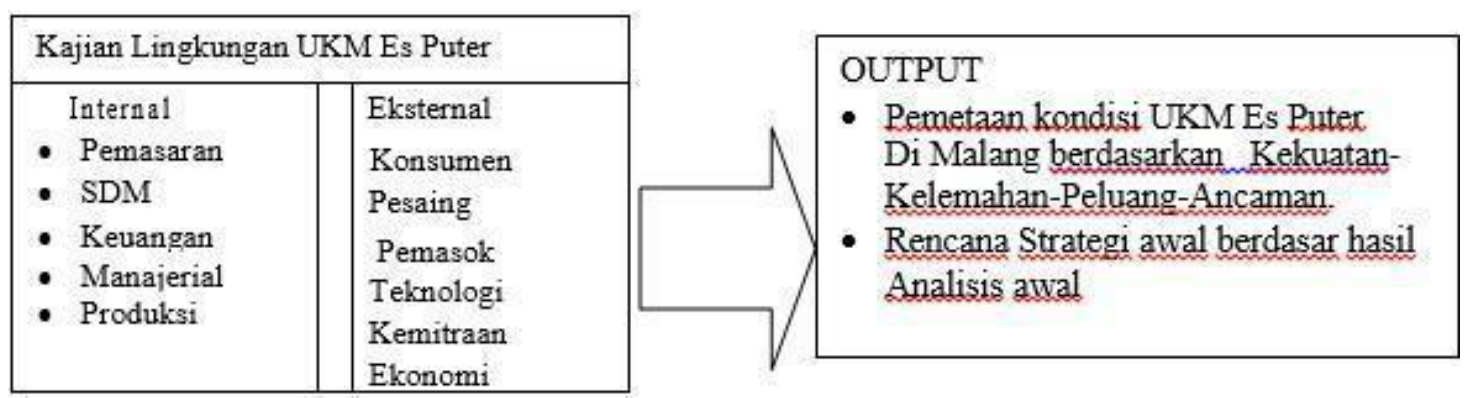

Gambar 1. Conceptual Frame Work

\begin{tabular}{|c|c|c|}
\hline $\begin{array}{l}\text { INTERNAL } \\
\text { FACTOR }\end{array}$ & $\begin{array}{l}\text { KEKUATAN } \\
\text { Aspek Pemasaran } \\
\text { - Kualitas produk } \\
\text { - Inovasi produk } \\
\text { Aspek SDM } \\
\text { - Kecukupan tenaga kerja } \\
\text { - Ketrampilan tenaga kerja } \\
\text { Aspek Manajerial } \\
\text { - Gaya kepemimpinan } \\
\text { - Pengontrolan usaha } \\
\text { Aspek Produksi } \\
\text { - Kelancaran proses produksi } \\
\text { - Peralatan produksi yang } \\
\text { - digunakan } \\
\text { - Kontinyuitas produksi }\end{array}$ & $\begin{array}{l}\text { KELEMAHAN } \\
\text { Aspek Pemasaran: } \\
\text { - Minimnya area keria di Malang } \\
\text { - Kemampuan memperluas cakupan dan } \\
\text { akses pasar } \\
\text { Aspek SDM } \\
\text { - Program pengembangan SDM } \\
\text { - Perolehan tenaga kerja dalam jangka } \\
\text { paniang } \\
\text { Aspek Manajerial } \\
\text { - Perencanaan usaha jangka panjang } \\
\text { - Manajemen usaha } \\
\text { Aspek Produksi } \\
\text { Kapasitas kemampuan produksi }\end{array}$ \\
\hline
\end{tabular}

Tabel 4. Mapping UKM Es Puter Berdasarkan Analisis SWOT dan Rekomendasi Strategi

Tabel 5. Matrik Faktor Strategi Internal

\begin{tabular}{|c|c|c|c|c|}
\hline 1 & Faktor Strategi Internal & Bobot & Rating & $\mathrm{B} \times \mathrm{R}$ \\
\hline & Kekuatan & & & \\
\hline & Bahan baku Es puter mudah didapat & 0,10 & 4 & 0,40 \\
\hline & SDM Lebih murah & 0,10 & 4 & 0,40 \\
\hline & Modal sendiri & 0,20 & 4 & 0,80 \\
\hline & Ketrampilan bekerja tingi & 0,05 & 3 & 0,15 \\
\hline & Kecukupan tenaga kerja & 0,05 & 3 & 0,15 \\
\hline & Sub Total & 0,50 & & 1,90 \\
\hline & Kelemahan & & & \\
\hline & Keterbatasan SDM & 0,05 & 2 & 0,10 \\
\hline & Masih minimnya pengetahuan alat Es puter & 0,05 & 2 & 0,10 \\
\hline & Minimnya area kerja di Malang & 0,15 & 2 & 0,30 \\
\hline & Sulitnya kerjasama dengan pemkot & 0,15 & 1 & 0,15 \\
\hline & $\begin{array}{l}\text { Minimnya Kemampuan } \\
\text { cakupan dan akses pasar }\end{array}$ & 0,10 & 1 & 0,10 \\
\hline & Sub Total & 0,50 & & 0,75 \\
\hline & Total & 1.00 & & 2,65 \\
\hline
\end{tabular}


deskriptif yang bersumber dari responden selaku sampel penelitian dan perilaku yang diamati. Jenis penelitian kualitatif yang digunakan dalam penelitian ini adalah Action research atau penelitian tindakan. Penelitian tindakan merupakan salah satu bentuk rancangan penelitian dimana peneliti mendeskripsikan menginterpretasi dan menjelaskan suatu situasi sosial pada waktu yang bersamaan. Dengan melakukan perubahan atau intervensi dengan tujuan perbaikan atau partisipasi. Dalam penelitian tindakan terjadi kolaborasi antara peneliti dengan client dalam mencapai tujuan. Adapun tahapan action research dalam studi ini adalah sebagaimana pada gambar 1 .

\section{Hasil Dan Pembahasan}

Hasil penelitian dijelaskan melalui pemaparan pada hasil analis SWOT dan rekomendasi strategi peningkatan daya saing berdasarkan pemetaan kekuatan, kelemahan, peluang, dan ancaman pada UKM Es Puter. Adapun hasil dan pembahasan penelitian dapat dipaparkan pada tabel 4-7 dan gambar 1-5 berikut ini.

Berdasarkan uji kecukupan data, maka jumlah sampel minimal yang digunakan dalam Penelitian adalah 40 koresponden.

Tabel 6. Matrik Faktor Strategi

\begin{tabular}{|c|c|c|c|c|}
\hline 1 & Faktor Strategi Internal & Bobot & Rating & $\mathrm{B} \times \mathrm{R}$ \\
\hline & Peluang & & & \\
\hline & Peluang pasar luar daerah masih terbuka & 0,15 & 4 & 0,60 \\
\hline & Pengembangan Kota Malang terbuka & 0,15 & 4 & 0,60 \\
\hline & Potensi pengembangan produk cukup besar & 0,15 & 3 & 0,45 \\
\hline & $\begin{array}{l}\text { Perhatian pemerintah pusat pada UKM ES } \\
\text { puterUcukup besar }\end{array}$ & 0,05 & 4 & 0,20 \\
\hline & $\begin{array}{l}\text { Memiliki pasar yang potensial untuk } \\
\text { bertumbuh }\end{array}$ & 0,05 & 4 & 0,15 \\
\hline & $\begin{array}{ll}\text { Sub Total } & \text { Sul }\end{array}$ & 0,55 & & 2,00 \\
\hline & Ancaman & & & \\
\hline & Adanya kompetitor & 0,05 & 2 & 0,10 \\
\hline & Aktifitas promosi kompetitor & 0,05 & 2 & 0,10 \\
\hline & Tingginya harga BBM & 0,10 & 1 & 0,15 \\
\hline & Pemberdayaan UKM tidak berpihak & 0,15 & 2 & 0,30 \\
\hline & $\begin{array}{l}\text { Tingginya Biaya dalam pengembangan } \\
\text { IKM }\end{array}$ & 0,10 & 2 & 0,20 \\
\hline & $\begin{array}{ll}\text { Sub Total } \\
\end{array}$ & 0,45 & & 0,75 \\
\hline & Total & 1.00 & & 2,75 \\
\hline
\end{tabular}

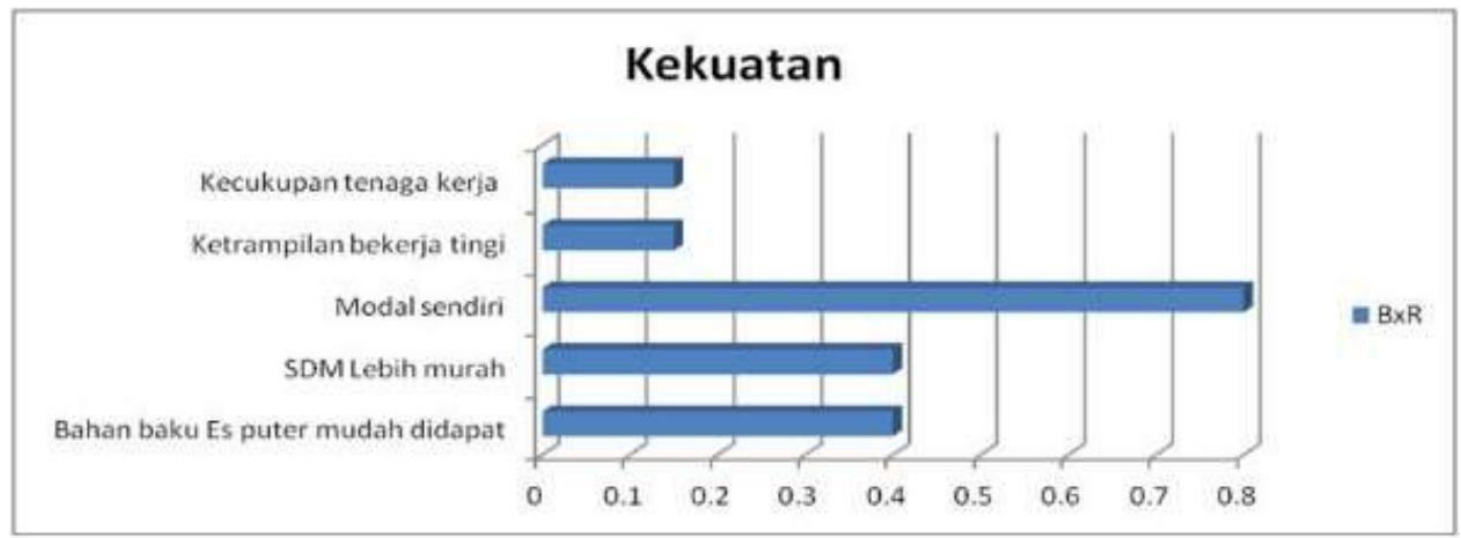

Gambar.2. Faktor Strategi Internal 


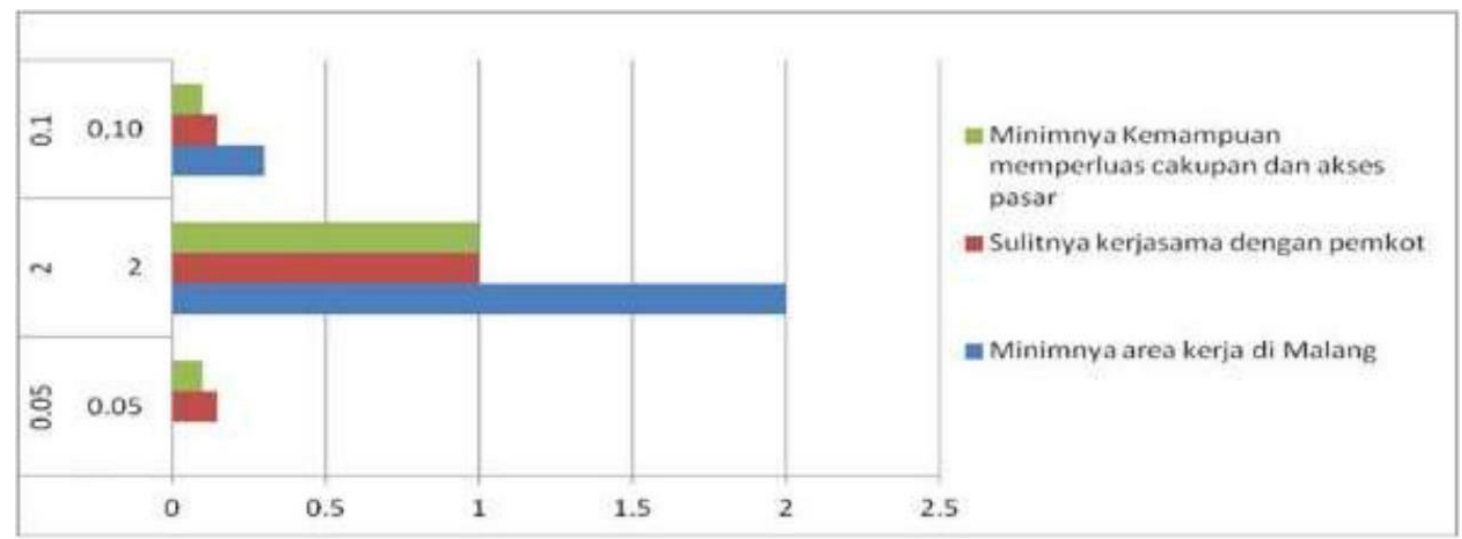

Gambar 3. Faktor Strategi Internal

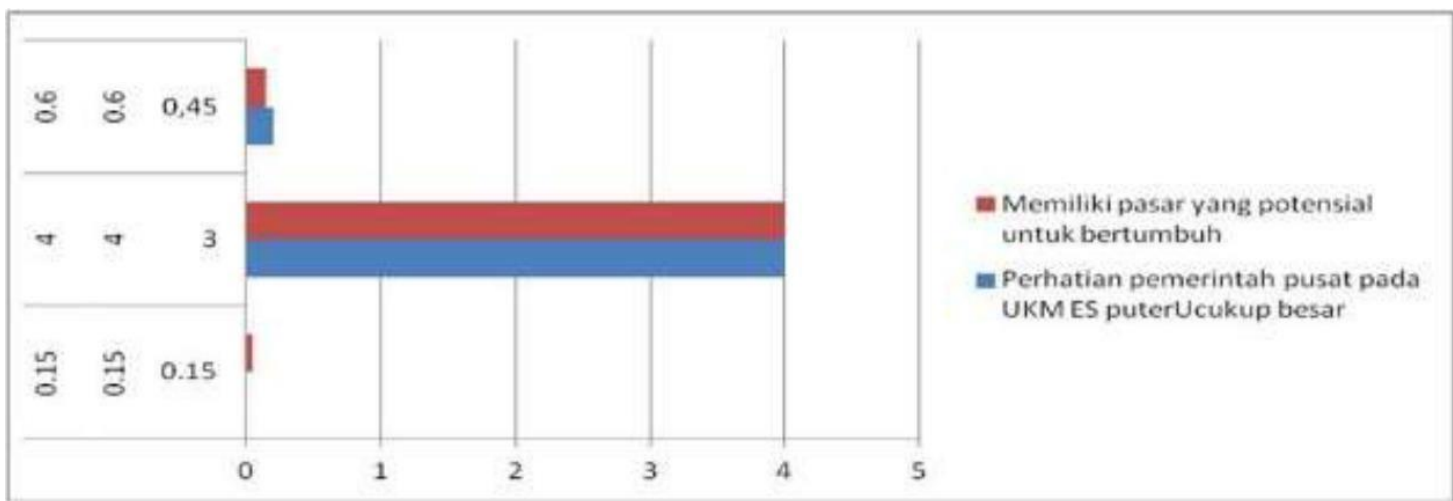

Gambar 4. Faktor Strategi Eksternal

Tabel 7. Hasil Matriks SWOT pemilihan strategi Pengembangan Sentra IKM Es Puter di Malang.

\begin{tabular}{|c|c|c|}
\hline$>$ & $\begin{array}{l}\text { STRENGHT (S) } \mathbf{1 , 9 0} \\
\text { Faktot - faktor kekuatan } \\
\text { Internal }\end{array}$ & $\begin{array}{l}\text { WEAKNESSES (W) } \mathbf{0 , 7 5} \\
\text { Faktot - faktor kelemahan } \\
\text { Internal }\end{array}$ \\
\hline OPPORTUNIES (O) & $\begin{array}{c}\text { STRATEGI SO } \\
\text { Strategi yang menggunakan } \\
\text { kekuatan untuk } \\
\text { memanfatkan peluang } \\
\text { jangka pendek menengah }\end{array}$ & $\begin{array}{c}\text { STRATEGI WO } \\
\text { Strategi yang meminimalkan } \\
\text { kelemahan untuk } \\
\text { memanfaatkan } \\
\text { peluang.jangkah panjang }\end{array}$ \\
\hline TREATHS (T) & STRATEGI ST & STRATEGI WT \\
\hline Faktor ancaman Eksternal & $\begin{array}{l}\text { Strategi yang menggunakan } \\
\text { kekuatan untuk mengatasi } \\
\text { ancaman jangka pendek }\end{array}$ & $\begin{array}{l}\text { Strategi yang meminimalkan } \\
\text { kelemahan dan menghindari } \\
\text { ancaman jangka menengah } \\
\text { dan panjang }\end{array}$ \\
\hline
\end{tabular}

\section{Kesimpulan}

Strategi pengembangan UKM Es puter diperlukan untuk memecahkan berbagai permasalahan, baik dari sisi daya saing produk, daya saing daerah, bahkan turut mendukung kearah daya saing global. Strategi diperlukan untuk mengarahkan agar UKM Es puter yang memiliki peran strategis dalam perekonomian 


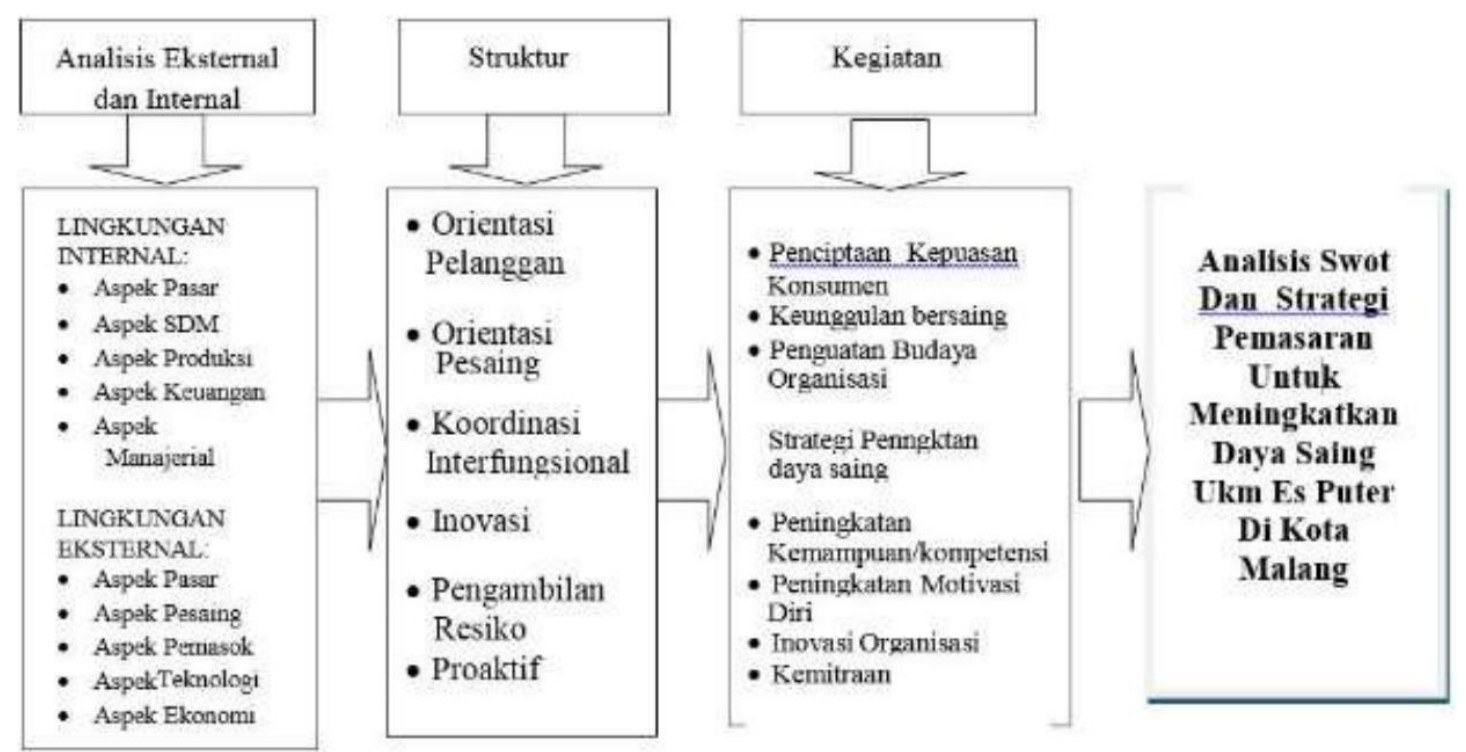

Gambar 5. Strategi Peningkatan Daya Saing UKM Es Puter

kita memiliki kinerja usaha yang lebih baik di masa yang akan datang. Berdasarkan analisis SWOT ditemukan bahwa: kekuatan UKM Es puter kota Malang adalah kualitas bahan baku sesuai dengan standar, hasil produk es yang bagus, berorientasi pada pelanggan, rata-rata SDM berketrampilan tinggi, harga jual produk, yang relatif sama dengan pesaing, jangkauan pemasaran yang luas. Kelemahan UKM es puter adalah penggunaan teknologi masih sederhana, variasi rasa masih sedikit, belum mencoba hasil penelitian dan pengembangan usaha, upah tenaga kerja masih dibawah UMR, tidak pernah melakukan pelatihan tenaga kerja, kurang promosi. Peluang UKM es puter adalah dukungan peraturan daerah yang cukup baik, pelayanan aparatur pemerintah cukup baik, kondisi, inovasi teknologi, dukungan teknologi yang baru terhadap produksi,. Ancaman bagi UKM es puter bahan baku yang dipakai mudah untuk didapat, persaingan bisnis yang ketat, kemudahan masuk pasar, daya beli masyarakat yang masih rendah, upah tenaga kerja yang rendah. Hasil dari analisis strategi pemasaran menunjukkan adanya peningkatan yang signifikan.

\section{Daftar Pustaka.}

[1] David, F.R. 2006. Manajemen Strategis :

Konsep. Jakarta . Salemba Empat.

[2] David, F.R. 2009. Manajemen Strategis

: Konsep.Jakarta. Salemba.

[3] David, Fred R., 2002. Manajemen Strategis Konsep, terjemahan, PT Prenhallindo, Jakarta
[4] Grant, R. M. 2010. Contemporary Strategy Analysis. 7th ed. John Wiley and Sons Ltd.

[5] Glueck, William F dan Jauch, Lawrence, 1989. Manajemen Strategi dan Kebijakan Perusahaan (2ed). Erlangga, Jakarta

[6] Hariadi, 2005. http://jurnalsdm.blogspot.com/ (diakses 20 April 2010)

[7] Hunger, J. D. and Wheelen, T. L., 2001. Strategic Management.1996. Fifth Editions. Addison-Wesley Publishing Company, Inc. Agung J. (penterjemah).2001. Manajemen Strategis. Andi.Yogyakarta.

[8] -------------1994. Competitive Advantage (Keunggulan Bersaing). Edisi Bahasa Indonesia.Binarupa Aksara, Jakarta

[9] Rangkuty, Freddy, 1997. Analisis SWOT Teknik Membedah Kasus Bisnis, Cetakan Kedua Penerbit PT. Gramedia Pustaka, Jakarta, 1997

[10]Umar, Husain.1999. Riset Strategi Perusahaan.PT Gramedia Pustaka Utama, Jakarta 